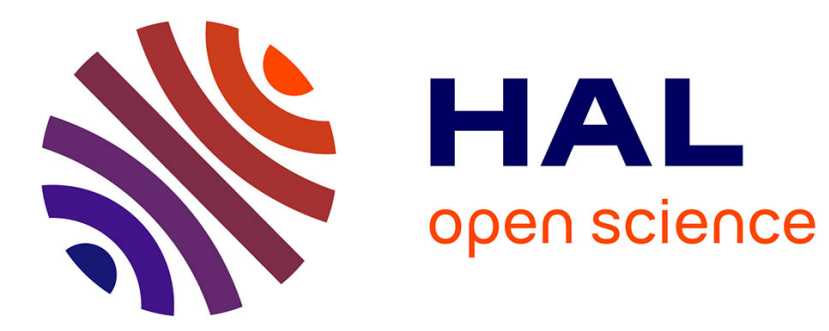

\title{
Influence of material removal on the dynamic behavior of thin-walled structures in peripheral milling
}

Vincent Thévenot, Lionel Arnaud, Gilles Dessein, Gilles Cazenave-Larroche

\section{To cite this version:}

Vincent Thévenot, Lionel Arnaud, Gilles Dessein, Gilles Cazenave-Larroche. Influence of material removal on the dynamic behavior of thin-walled structures in peripheral milling. Machining Science and Technology, 2006, vol. 10, pp. 275-287. 10.1080/10910340600902082 . hal-00840332

\section{HAL Id: hal-00840332 \\ https://hal.science/hal-00840332}

Submitted on 2 Jul 2013

HAL is a multi-disciplinary open access archive for the deposit and dissemination of scientific research documents, whether they are published or not. The documents may come from teaching and research institutions in France or abroad, or from public or private research centers.
L'archive ouverte pluridisciplinaire HAL, est destinée au dépôt et à la diffusion de documents scientifiques de niveau recherche, publiés ou non, émanant des établissements d'enseignement et de recherche français ou étrangers, des laboratoires publics ou privés. 


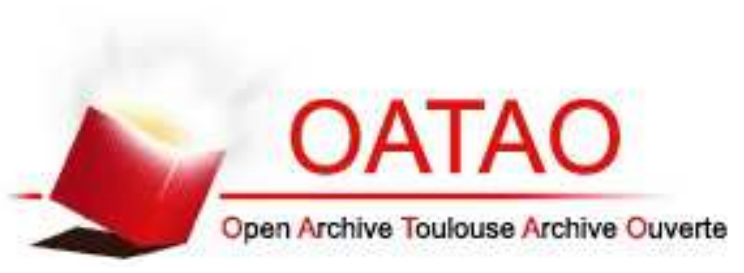

\section{Open Archive Toulouse Archive Ouverte (OATAO)}

OATAO is an open access repository that collects the work of Toulouse researchers and makes it freely available over the web where possible.

This is an author-deposited version published in: http://oatao.univ-toulouse.fr/ Eprints ID: 6389

To link to this article: DOI:10.1080/10910340600902082

http://dx.doi.org/10.1080/10910340600902082

\section{To cite this version:}

Thévenot, Vincent and Arnaud, Lionel and Dessein, Gilles and CazenaveLarroche, Gilles Influence of material removal on the dynamic behavior of thinwalled structures in peripheral milling. (2006) Machining Science and Technology, 10 (3). pp. 275-287. ISSN 1091-0344

Any correspondence concerning this service should be sent to the repository administrator: staff-oatao@inp-toulouse.fr 


\title{
INFLUENCE OF MATERIAL REMOVAL ON THE DYNAMIC BEHAVIOR OF THIN-WALLED STRUCTURES IN PERIPHERAL MILLING
}

\author{
V. Thevenot $\square \quad$ Turbomeca, Bordes Cedex, France \\ L. Arnaud and G. Dessein $\square$ Laboratoire Génie de Production, Ecole Nationale \\ d'Ingénieurs de Tarbes, Tarbes Cedex, France \\ G. Cazenave-Larroche $\square$ Turbomeca, Bordes Cedex, France
}

Machining is a material removal process that alters the dynamic properties during machining operations. The peripheral milling of a thin-walled structure generates vibration of the workpiece and this influences the quality of the machined surface. A reduction of tool life and spindle life can also be experienced when machining is subjected to vibration. In this paper, the linearized stability lobes theory allows us to determine critical and optimal cutting conditions for which vibration is not apparent in the milling of thin-walled workpieces. The evolution of the mechanical parameters of the cutting tool, machine tool and workpiece during the milling operation are not taken into account. The critical and optimal cutting conditions depend on dynamic properties of the workpiece. It is illustrated how the stability lobes theory is used to evaluate the variation of the dynamic properties of the thinwalled workpiece. We use both modal measurement and finite element method to establish a 3D representation of stability lobes. The $3 D$ representation allows us to identify spindle speed values at which the variation of spindle speed is initiated to improve the surface finish of the workpiece.

Keywords Thin Wall Machining, Chatter, 3D Stability Lobes, Modal Vibrations, Variable Spindle Speed

\section{INTRODUCTION}

During machining operation vibration between the tool and the workpiece often occurs. Such vibration induced by chatter, influences the surface quality, dimensional accuracy, and to a lesser extent the tool and spindle lives. Therefore, it is necessary to prevent the vibration in machining operations. In the 1950s, S.A. Tobias (1), J. Tlusty (2) and H.E. Merrit (3) studied the vibration of the tool in the case of orthogonal cutting

Address correspondence to G. Dessein, Laboratoire Génie de Production, Ecole Nationale d'Ingénieurs de Tarbes, 47 Avenue d' Azereix BP1629, Tarbes Cedex, 65000 France. E-mail: gilles.dessein@ enit.fr 
operations and developed the linearized stability lobes theory. The theory makes it possible to predict cutting conditions for which vibration may appear. At the end of 1960, Sridhar $(4,5)$ developed the stability lobes theory for the milling process, and in the middle of the 1990, Altintas (6) presented geometrical formulation and analytical method to determine the stability limits for the tool and/or the workpiece for milling operations. This theory is mainly used to reduce the tool vibration, but can also be used to study the vibration of the workpiece (7-12). When a thin walled structure is machined, its dynamic characteristics change with respect to discrete time and hence the stability lobes are not valid for the entire machining operation. We compute a 3D representation of the stability lobes, which allows us to determine critical and optimal cutting conditions for every moment of the machining operation. The first and second dimensions are a representation of the classical stability lobes and the third dimension represents the relative tool position with respect to the workpiece.

\section{STABILITY LOBES THEORY}

This work is mainly based on the stability lobes theory developed by Y. Altintas and E. Budak $(6,10,13,14)$ and on the consideration of a simplified regenerative chatter model with one degree of freedom. Our main objective is to show how to compute the stability lobes for continuous milling operation. The governing equations of the model provided us an opportunity to plot the stability lobes. If a reader wants to understand details of the classical procedures for computing stability lobes, the work of Y. Altintas and E. Budak provides fundamental illustrations.

For the investigation the following assumptions are made:

(i) The workpiece is flexible as compared to the tool.

(ii) The workpiece can locally be considered as a rigid body in the zone where the workpiece and the tool are in engagement.

(iii) The workpiece moves along the direction y, which is the direction out of the plane of the thin wall.

The resulting governing equations of the displacement induced by the vibration are of the form

$$
\ddot{y}+2 \delta \omega \dot{y}+\omega^{2} y=\frac{\omega^{2}}{k} F
$$

where $\delta=c /(2 \sqrt{m k})$ and $\omega^{2}=k / m$. In this equation, $\delta$ is the damping ratio, $\omega$ is the undamped natural frequency of the considered mode (the mode that governs the chatter instability), $k$ is the stiffness and $F$ is the 
contribution of the cutting force $F_{c}$ at the mode. The cutting force is made up of tangential and radial cutting forces. We use the linearized form of the cutting forces $F_{t}=k_{t}\left(a_{p}\right)^{\alpha}\left(a_{e}\right)^{\beta}$ and $F_{r}=k_{r} F_{t}$ for $\alpha=\beta=1$ where $F_{t}$ and $F_{r}$ are respectively the tangential and radial cutting forces. $k_{t}$ and $k_{r}$ are the corresponding tangential and radial milling force coefficients and $a_{p}$ and $a_{e}$ are the axial and radial depth of cut, accordingly.

\section{Computation of the Stability Lobes}

We use an orthogonal cutting model even though the lobes shape is not exactly the same as an oblique cutting model. Given the measurement inaccuracy for certain cutting parameters, we use an orthogonal cutting model that is easily fitted with the experimental data. The stability lobes diagram represents the critical axial depth of cut, $\left(a_{p}\right)_{\text {crit }}$ and the spindle speed, $\Omega$. The lobes are plots of the parametric functions $\left(a_{p}\right)_{c r i t}=a_{p}\left(\omega_{\mathrm{c}}\right)$ and $\Omega=\Omega\left(\omega_{\mathrm{c}}\right)$, where the parameter $\omega_{\mathrm{c}}$ is the vibration frequency of the workpiece. The parametric functions are obtained from the regenerative model shown in Figure 1. A systematic derivation of the functions can be found in $(13,14)$. In those publications, the limiting condition of stability with regard to the parametric function $\left(a_{p}\right)_{c r i t}=a_{p}\left(\omega_{\mathrm{c}}\right)$, in particular, is given by

$$
\left(a_{p}\right)_{c r i t}=\frac{2 \pi}{z \alpha_{y y} k_{t} \Re e\left[G_{y}\left(j \omega_{c}\right)\right]}
$$

where $z$ is the number of teeth on the cutter and $\Re e\left[G_{y}\left(j \omega_{c}\right)\right]$ is the real part of the structural transfer function of the vibrating system. Equation (2) is simply obtained by solving the corresponding characteristic equation of Equation (1) at criticality. $\alpha_{y y}$ is the directional dynamic milling coefficient

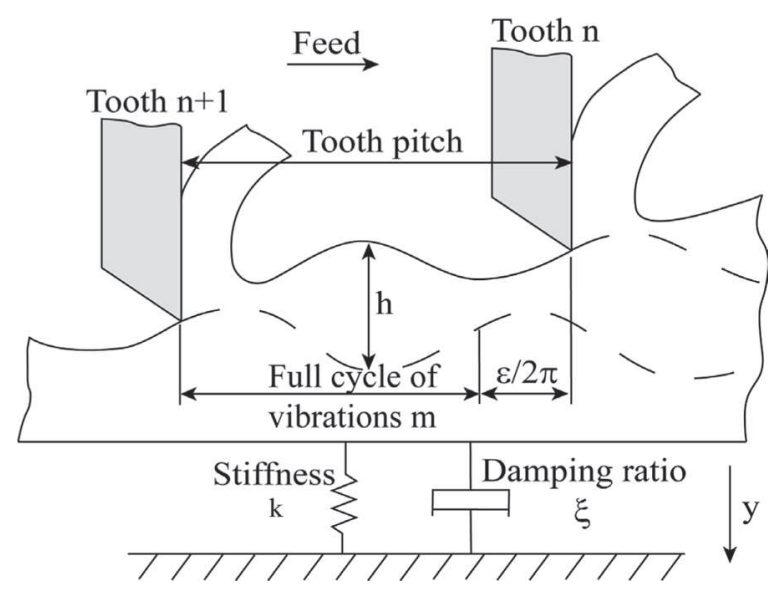

FIGURE 1 Regenerative cutting model of a single degree of freedom system. 


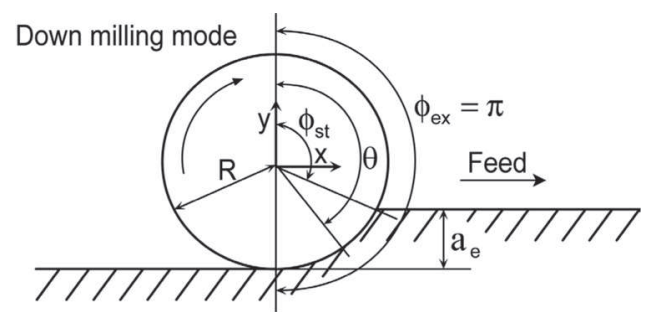

FIGURE 2 Start and exit angle in down milling.

in the y direction, and this is described by

$$
\alpha_{y y}=-\frac{1}{2}\left\{\cos 2 \phi_{e x}+2 k_{r} \phi_{e x}+k_{r} \sin 2 \phi_{e x}-\cos 2 \phi_{s t}-2 k_{r} \phi_{s t}-k_{r} \sin 2 \phi_{s t}\right\}
$$

where $\phi_{\mathrm{ex}}$ is the exit angle of the tool and $\phi_{\mathrm{st}}$ is the start angle of the tool (see Figure 2).

The expression for $\Re e\left[G_{y}\left(j \omega_{c}\right)\right]$ is given by

$$
\Re e\left[G_{y}\left(j \omega_{c}\right)\right]=\frac{1}{k}\left[\frac{1-d^{2}}{\left(1-d^{2}\right)^{2}+4 \delta^{2} d^{2}}\right]
$$

where $d=\omega_{\mathrm{c}} / \omega, \omega$ is the natural frequency of the mode, $\mathrm{k}$ is the stiffness and $\delta$ is the damping ratio.

The limiting stability conditions with respect to the function $\Omega=\Omega\left(\omega_{\mathrm{c}}\right)$ is given by

$$
\Omega=\frac{60 \omega_{c}}{z\left[2 n \pi+2 \pi-2 \arctan \left[\frac{d^{2}-1}{2 \delta d}\right]\right]}
$$

where $\mathrm{n}$ is the number of full vibration cycle between the two teeth.

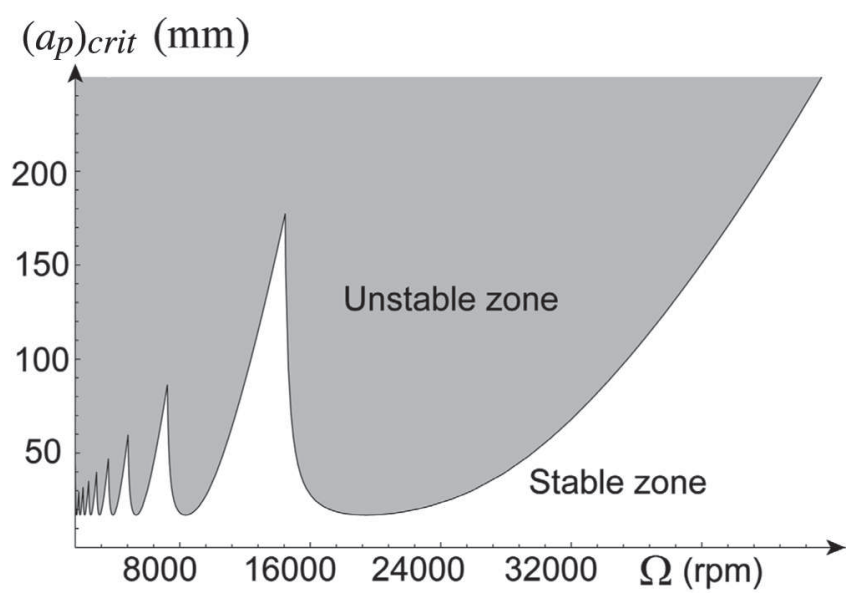

FIGURE 3 Layout of linear stability lobes. 
To plot the stability lobes, the parameter $\omega_{\mathrm{c}}$ must be higher than the natural frequency of the system. In this regard, we obtain for one natural mode and for different values of $n$, the diagram shown in Figure 3.

\section{VARIATIONS OF THE DYNAMIC CHARACTERISTICS}

When a thin walled structure is machined, we often see that the machined surface is not homogeneous in terms of surface quality. The dynamic behaviour of the workpiece depends on the tool position and moreover, the dynamic behaviour of the vibrating mode is different when the excitation force is at a node or an antinode. Incidentally, we introduce a third dimension in the stability lobes diagram, which is the direction $x$ of the machining operation (see Figure 4).

The modal representation of the displacement for the propose vibration model is described by

$$
y(x, t)=\sum_{i=1}^{\infty} \Phi_{i}(x) q_{i}(t)
$$

in which $q_{i}(t)$ represents a solution of the modal equation

$$
m_{i} \ddot{q}_{i}(t)+c_{i} \dot{q}_{i}(t)+k_{i} q_{i}(t)=f_{i}
$$

and $f_{i}=\Phi_{i}\left(x_{0}\right) F_{c}$. In these equations, $\Phi_{\mathrm{i}}\left(x_{0}\right)$ is the modal displacement at the location $x_{0}$ and $F_{c}$ is the cutting force.

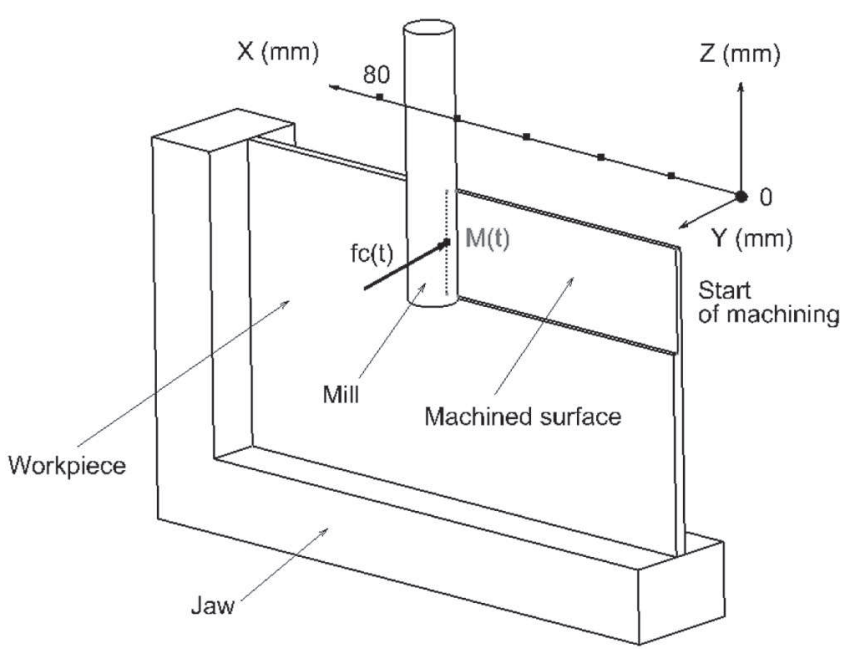

FIGURE 4 Machining configuration and application point of the cutting force in the test. 
With the excitation of one mode by the localized cutting force at $x_{0}$, for instance, the displacement of the workpiece is given by

$$
y\left(x_{0}, t\right)=\Phi_{i}\left(x_{0}\right) q_{i}(t)
$$

where the substitution of this equation and its derivatives into (7) yields

$$
\frac{k_{i}}{\Phi_{i}^{2}\left(x_{0}\right)} \ddot{y}\left(x_{0}, t\right)+\frac{c_{i}}{\Phi_{i}^{2}\left(x_{0}\right)} \dot{y}\left(x_{0}, t\right)+\frac{m_{i}}{\Phi_{i}^{2}\left(x_{0}\right)} y\left(x_{0}, t\right)=F_{c}
$$

and $\mathrm{k}_{\mathrm{i}}, \mathrm{c}_{\mathrm{i}}$, and $\mathrm{m}_{\mathrm{i}}$ are the modal stiffnesses, damping coefficients and masses, respectively.

Imposing Equation (9) onto Equation (1), we thus obtain

$$
m=\frac{m_{i}}{\Phi_{i}^{2}\left(x_{0}\right)}, c=\frac{c_{i}}{\Phi_{i}^{2}\left(x_{0}\right)}, k=\frac{k_{i}}{\Phi_{i}^{2}\left(x_{0}\right)}
$$

where $k_{i}, m_{i}$, and $\Phi_{i}\left(x_{0}\right)$ are obtained by determining the natural modes using finite element method. For different step position $x$ of the tool and for each natural mode, we determine the modal displacement in the cutting zone $\Phi_{\mathrm{i}}\left(x_{0}\right)$. Then, with the determination of the stiffness $k$ using Equation (10), the stability lobes are constructed.

According to the expression for the stiffness in Equation (10), it can be seen that $k$ is larger when the tool is at a node than when it is at an antinode. Also, it can be seen that the critical axial depth of cut is higher at a node than at an antinode (see Equations (2) and (4)). The variation of the apparent stiffness $k$ of the second mode of the workpiece is shown in Figure 5.

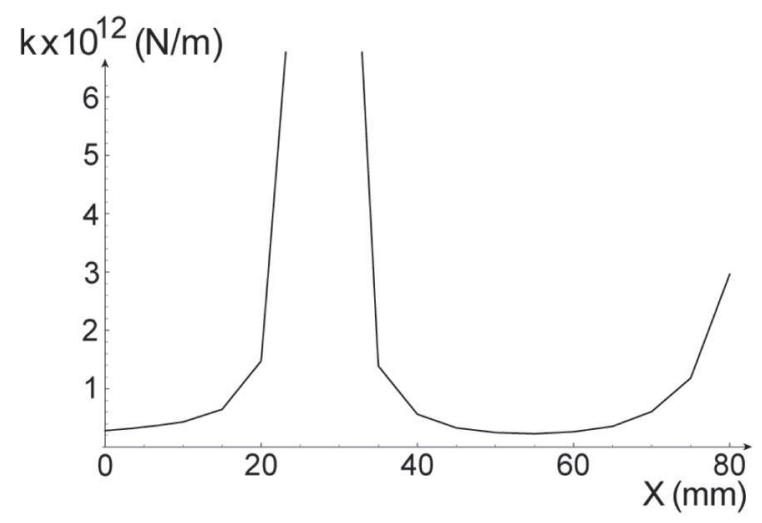

FIGURE 5 Variation of the apparent stiffness of the second mode of the test during machining. 


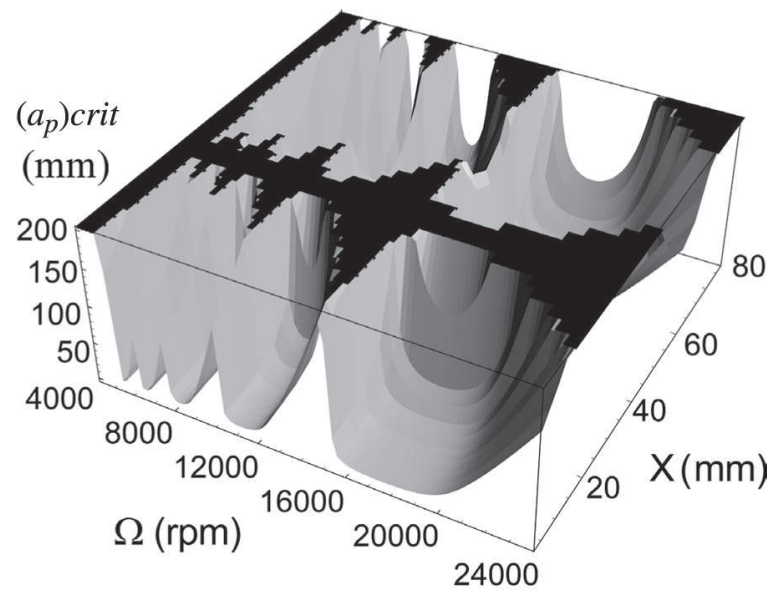

FIGURE 6 3D lobes of the second mode of the test with variation in the apparent stiffness.

For each position $x$ in Figure 6, a crossectional 2D stability lobes can be constructed (see Figure 3). The 3D stability lobes represent the second mode of the test and the parameters in Table 1 have been used in the computation. There are infinitely many stability lobes for the modes.

\section{Variation of Natural Frequencies and Dynamic Parameters}

Machining is a chip removal process. When the material removal is significant, the dynamic properties of the workpiece change according to the tool position. The material removal influences mainly the natural frequencies. In this regard, the critical axial depth of cut and optimal spindle speed will vary as the tool moves with respect to the workpiece. This can be seen in Equations (2), (4) and (5). Figure 8 illustrates the 3D lobes of the second mode and the impact of varying the natural frequency. For a real

TABLE 1 Parameters of the Second Mode of the Test During Machining

\begin{tabular}{ll}
\hline Parameters & \multicolumn{1}{c}{ Values } \\
\hline$\omega_{0}$ & $12560 \mathrm{rad} / \mathrm{s}$ \\
$\xi$ & 0.00406 \\
$K_{t}$ & $1414 \mathrm{MPa}$ \\
$K_{r}$ & 0.8 \\
$z$ & 4 \\
$D$ & $12 \mathrm{~mm}$ \\
$A_{p}$ & $20 \mathrm{~mm}$ \\
$A_{e}$ & $1 \mathrm{~mm}$ \\
$X$ & $80 \mathrm{~mm}$ \\
\hline
\end{tabular}




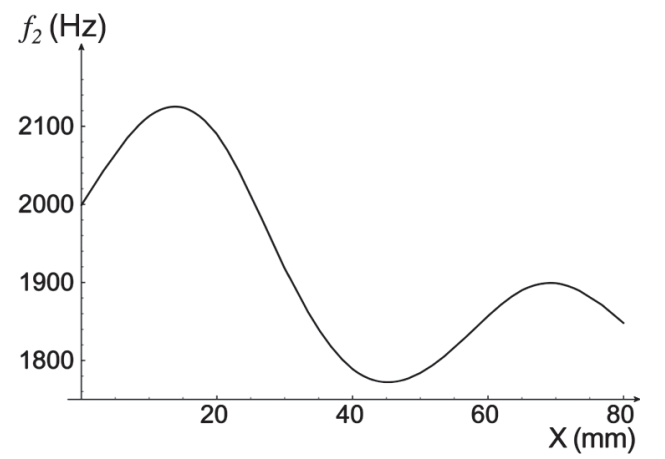

FIGURE 7 Variation of the natural frequency of the second mode during machining.

machining operation one has to take into account the other modes. For the construction of the stability lobes in Figure 8, the parameters for Figure 6 are used with the exception of $\omega_{0}$. The values for $\omega_{0}$ vary with the machining operation. The variation of the values of $\omega_{0}$ for the second mode is represented in Figure 7 and this has been obtained for $a_{p}=20 \mathrm{~mm}$. This illustrates the fact that the variation of the natural frequency is dependent on $a_{p}$. Three dimensional lobes for each value of $a_{p}$ can be constructed as well. The variation of the natural frequency is evaluated by creating new finite element models for multiple tool locations and with variation of the wall thickness of the machined surface. Ten step finite element models are used. Taken into account of the variation of the natural frequencies and the variation of the apparent stiffnesses, 3D lobes for the second mode of the test are constructed (see Figure 9). In most cases, one has to take into

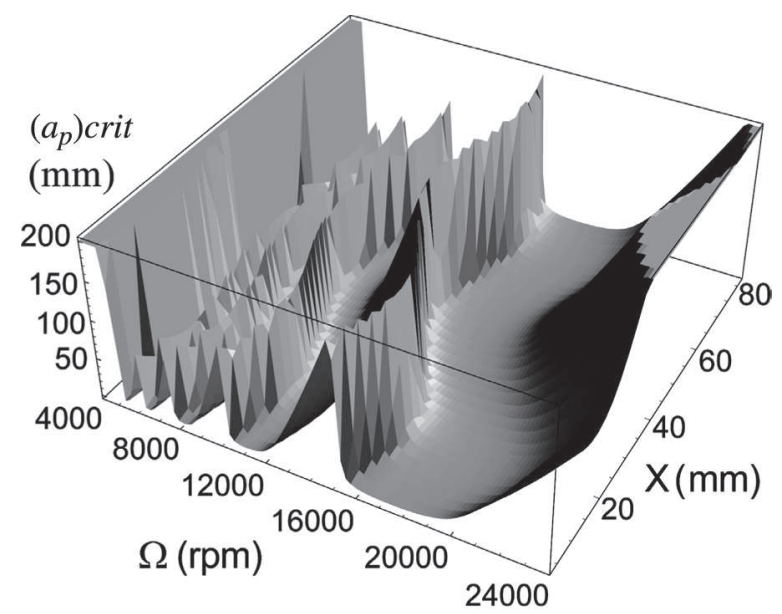

FIGURE 8 3D lobes of the second mode of the test with variation in the natural frequency. 


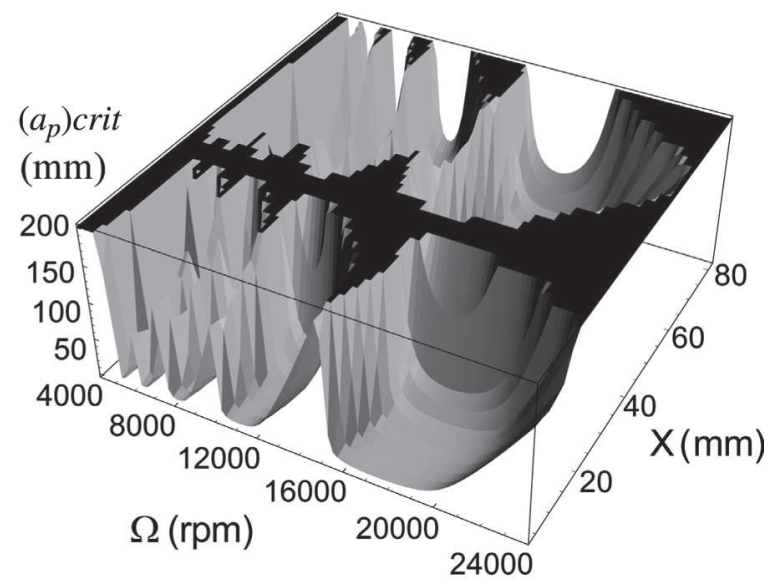

FIGURE 9 3D lobes of the second mode with variation in the apparent stiffness and natural frequency.

account these two types of variations because it is usually not possible to find a constant optimal spindle speed.

To obtain the variation of the dynamic parameters of the workpiece, we carry out a parametric finite element analysis with the parameter of the tool position shown in Figure 10. For each step of the analysis and for each mode, we determine the natural frequency, modal stiffness and displacement of the tool position. In this way, the variation of the natural frequencies and the apparent stiffnesses for the machining operation are evaluated. The stability lobes are adjusted by using the measured natural frequencies before milling.

\section{TEST VALIDATION}

We consider the peripheral down-milling of an aluminium plate as shown in Figure 4. Its thickness is $2 \mathrm{~mm}$ and has two perpendicular sides that are embedded together. The programmed radial depth of cut is $1 \mathrm{~mm}$ and the feed rate is $0.05 \mathrm{~mm} /$ tooth. We use a cylindrical milling cut-
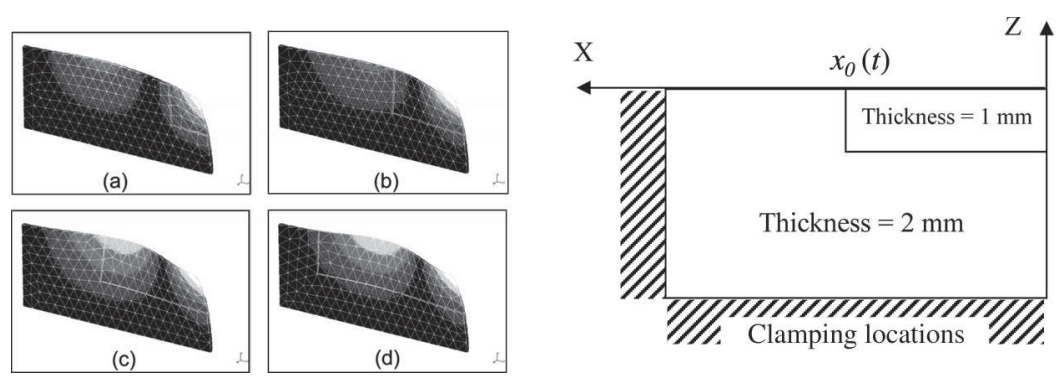

FIGURE 10 Parametric computation of the second mode. 


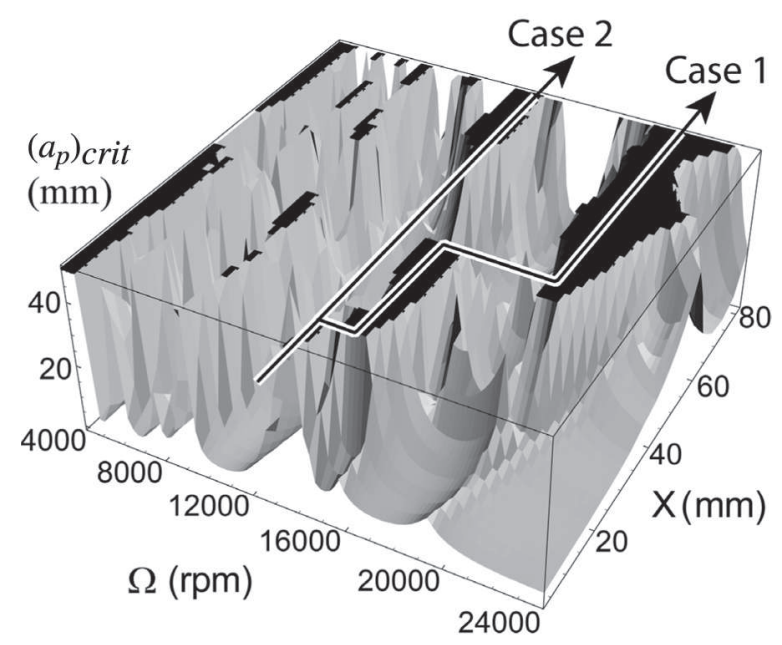

FIGURE 11 3D lobes for the five first modes of the test.

ter with diameter $12 \mathrm{~mm}, 4$ teeth and helix angle being $45^{\circ}$. The length of the machining operation is $80 \mathrm{~mm}$ and the axial depth of cut is $20 \mathrm{~mm}$. Two identical workpieces are machined under the same dynamic conditions. To minimize the occurrence of errors, the stiffness, damping coefficient and other essential dynamic parameters are measured for each workpiece. During the machining operation, we observed that the first five modes are the most violent modes. The 3D stability lobes representing these modes for each workpiece are depicted in Figure 11. The most influential parameter for the selection of spindle speed is the natural frequency. The frequencies are found to be identical for both workpieces.

It can be seen from Figure 11 that one cannot find a constant spindle speed for which the dynamic behaviour of the workpiece is stable during the entire milling operation. For this reason, we use different spindle speeds in order to maintain the stability of the milling operation. During the first phase of milling operations, we use the spindle speed values as presented in Table 2. Figure 12 contains the resulting surface finish generated by the spindle speeds.

With the table drives of the machine tool being at the locations $\mathrm{x}=20 \mathrm{~mm}$ and $\mathrm{x}=35 \mathrm{~mm}$, we observe changes in spindle speed and

TABLE 2 Variation of Spindle Speed with Respect to the Tool Position

\begin{tabular}{lc}
\hline Location X $(\mathrm{mm})$ & Spindle speed $\Omega(\mathrm{rpm})$ \\
\hline $0-20$ & 14,000 \\
$20-35$ & 16,000 \\
$35-80$ & 21,000 \\
\hline
\end{tabular}




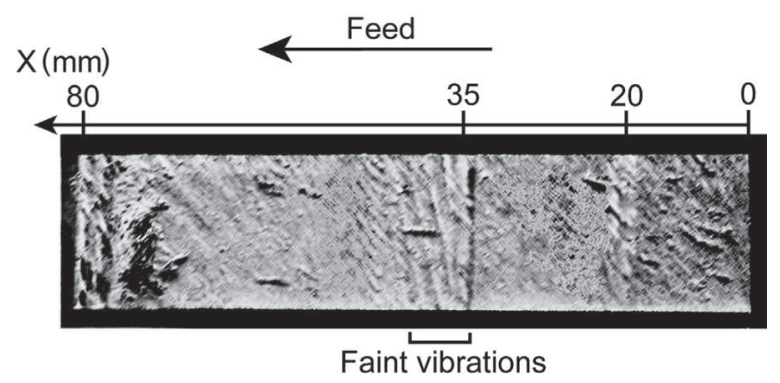

FIGURE 12 Resulting surface finish with variable spindle speed.

surface finish. Modulation of the spindle speed results to the stopping of the linear axis of the CNC machine tool. Although the marks at the locations $\mathrm{x}=20 \mathrm{~mm}$ and $\mathrm{x}=35 \mathrm{~mm}$ have adverse implications with respect to surface finish and spindle speed fluctuation, they however, provide an opportunity to identify regions where spindle speed values are different.

For the second phase of the milling operation the variation of the apparent stiffness and frequencies are not taken into consideration. The stability lobes for this situation are presented in Figure 13. The modulation of spindle speed is initiated at 14,000 rpm.

To compare the first and second phases of milling operation of the thin walled workpieces, we stop the linear axes at the same locations of the table drive along the $\mathrm{x}$ axis, namely $\mathrm{x}=20 \mathrm{~mm}$ and $\mathrm{x}=35 \mathrm{~mm}$. The resulting surface finish is shown in Figure 14.

Between $x=20 \mathrm{~mm}$ and $\mathrm{x}=35 \mathrm{~mm}$, one can see that the quality of the surface finish for the two phases of the milling operations are similar.

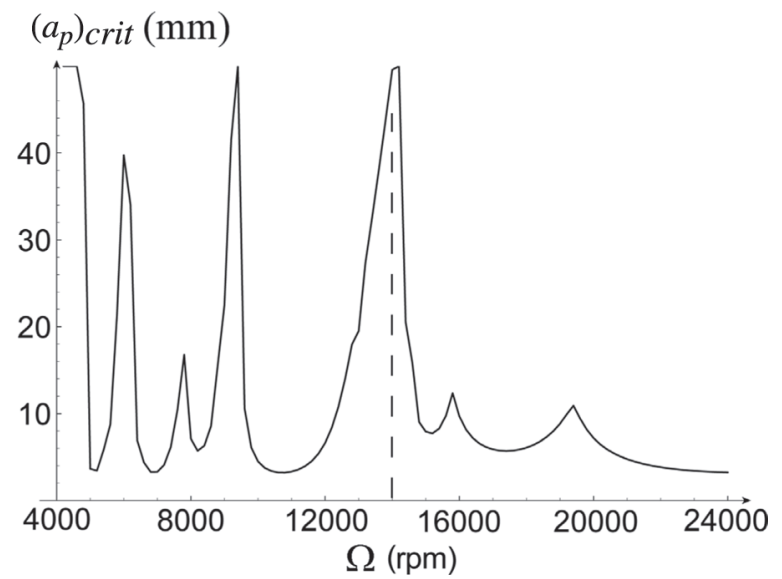

FIGURE 13 Standard representation of the stability lobes for the test. 


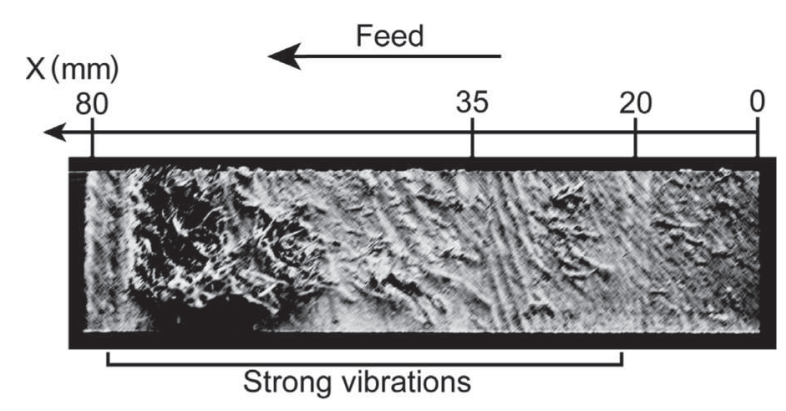

FIGURE 14 Resulting surface finish with constant spindle speed.

However between $\mathrm{x}=35 \mathrm{~mm}$ and $\mathrm{x}=80 \mathrm{~mm}$, the resulting quality of the surface finish for the first phase milling operation is better than the surface quality of the second phase milling operation. This shows, in particular, the significant of taking into account the variations of the dynamic parameters. We have shown that standard procedures of stability lobes are not sufficient for appropriate selection of the cutting conditions as the tool moves with respect to the workpiece.

Furthermore, it is observed that regenerative model vibration analysis is valid in an established mode. The time necessary for a significant variation of the stiffness and frequency must be longer than the time required for the system to reach such an established mode. The cutting tests show that the stability transition is faster than the variation of the dynamic parameters.

\section{CONCLUSIONS}

In this article, we have shown that standard procedures for the construction of stability lobes are not sufficient if one is interested in investigating the dynamics of thin walled structures. The dynamic properties of thin walled structures vary as the tool moves with respect to the workpiece. We introduce a third dimension in the stability lobes to denote the tool position. First, the apparent stiffnesses of the thin walled workpiece are varied during milling and when the tool passes from nodes to antinodes. The critical axial depth of cut is not constant for each natural mode. Second, the natural frequencies of the workpiece are varied with the tool passing from nodes to antinodes. The 3D stability lobes are constructed for both cases, and from the lobes non constant optimal spindle speed are derived.

The modulation of the spindle speed is initiated at $14,000 \mathrm{rpm}$. The experimental tests show that the variation of frequency and stiffness has a significant influence on the quality of the surface finish of the workpiece. It is found that milling with spindle speed variation does illustrate an important solution for the dynamic analysis of thin walled machining. 
Further investigation of the dynamic stability of thin walled milling operation will focus on the continuous variation of the spindle speed in order to avoid the marks due to the stopping of the linear axes. Nonlinear stability lobes will be constructed for a wide range of cutting conditions and spindle speed variations.

\section{REFERENCES}

[1] Tobias, S.A. and Fishwick, W. (1958). A Theory of Self Regenerative Chatter. The Engineer, 205: 199-203.

[2] Tlusty, J. and Polacek, M. (1963). The Stability of Machine Tools Against Self Excited Vibrations in Machining. Proceedings of the ASME International Research in Production Engineering, Pittsburgh, Pennsylvania, 465-474.

[3] Merrit, H.E. (1965). Theory of Self Excited Machine Tool Chatter. Journal of Engineering for Industry ASME, 17:447-454.

[4] Sridhar, R., Hohn, R.E., and Long, G.W. (1968). General Formulation of the Milling Process Equation. Journal of Engineering for Industry ASME, 90:317-324.

[5] Sridhar, R., Hohn, R.E., and Long, G.W. (1968). A Stability Algorithm for the General Milling Process. Journal of Engineering for Industry ASME, 90:330-334.

[6] Altintas, Y. and Budak, E. (1995). Analytical Prediction of Stability Lobes in Milling. Annals of the CIRP, 44(1):357-362.

[7] Arnaud, L. and Dessein, G. (2003). Application of the Stability Lobes Theory to Milling of Thin Workpiece. In Recent Advances in Integrated Design and Manufacturing in Mechanical Engineering, Gogu, G., Coutellier, D., Chedmail, P., and Ray, P., eds., Kluwer Academic Publishers, Norwell Massachusetts, USA, pp. 271-280.

[8] Herranz, S., Campa, F.J., López de Lacalle, L.N., Rivero, A., Lamikiz, A., Ukar, E., Sánchez, J.A., and Bravo, U. (2005). The Milling of Airframe Components with Low Rigidity: A General Approach to Avoid Static and Dynamic Problems. Proceedings of the I MECH E Part B Journal of Engineering Manufacture, 219:789-802.

[9] Ismail, F. and Ziaei, R. (2002). Chatter Suppression in Five-axis Machining of Flexible Part. Journal of Tools and Manufacture, 42:115-122.

[10] Budak, E. (1987). Mechanics and Dynamics of Milling Thin Walled Structures. Thesis, University of British Columbia, Vancouver, British Columbia, Canada.

[11] Jacobs, T.P. (2002). Specialized Procedures for Efficient High Speed Machining. Thesis, University of North Carolina at Charlotte, Charlotte, North Carolina, USA.

[12] Lapujoulade, F., Mabrouki, T., and Raïssi, K. (2002). Vibratory Behaviour Prediction of Thinwalled Parts During Lateral Finish Milling. Mechanic E゚ Industries, 3:403-418.

[13] Budak, E. and Altintas, Y. (1998). Analytical Prediction of Chatter Stability in Milling-Part I: General Formulation. Journal of Dynamic Systems, Measurement, and Control ASME, 120:22-30.

[14] Budak, E. and Altintas, Y. (1998). Analytical Prediction of Chatter Stability in Milling-Part II: Application of the General Formulation to Common Milling Systems. Journal of Dynamic Systems, Measurement, and Control ASME, 120:31-36. 